OPEN ACCESS

Edited by:

Layne Kalbfleisch,

George Washington University,

United States

Reviewed by:

Angela Jocelyn Fawcett,

Swansea University, United Kingdom

Pin-Ju Chen,

St. Mary's Junior College of Medicine,

Nursing and Management, Taiwan

${ }^{*}$ Correspondence:

Giseli D. Germano

giseliger@yahoo.com.br

Specialty section:

This article was submitted to

Educational Psychology,

a section of the journal

Frontiers in Psychology

Received: 06 April 2017

Accepted: 22 September 2017

Published: 27 October 2017

Citation:

Germano GD, César ABPC and

Capellini SA (2017) Screening

Protocol for Early Identification of

Brazilian Children at Risk for Dyslexia.

Front. Psychol. 8:1763.

doi: 10.3389/fpsyg.2017.01763

\section{Screening Protocol for Early Identification of Brazilian Children at Risk for Dyslexia}

\author{
Giseli D. Germano ${ }^{1,2 *}$, Alexandra B. P. de C. César ${ }^{1,3}$ and Simone A. Capellini ${ }^{1}$ \\ 1 Investigation Learning Disabilities Laboratory, Department of Speech and Hearing Sciences, São Paulo State University \\ "Júlio de Mesquita Filho" (UNESP), Marilia, Brazil, ${ }^{2}$ Department of Special Education, São Paulo State University "Júlio de \\ Mesquita Filho" (UNESP), Marilia, Brazil, ${ }^{3}$ Speech and Hearing Sciences Department, São Paulo State University "Júlio de \\ Mesquita Filho" (UNESP), Marilia, Brazil
}

Early identification of students at risk of dyslexia has been an educational challenge in the past years. This research had two main goals. First, we aimed to develop a screening protocol for early identification of Brazilian children at risk for dyslexia; second, we aimed to identify the predictive variables of this protocol using Principal Component Analysis. The major step involved in developing this protocol was the selection of variables, which were chosen based on the literature review and linguistic criteria. The screening protocol was composed of seven cognitive-linguistic skills: Letter naming; Phonological Awareness (which comprises the following subtests: Rhyme production, Rhyme identification, Syllabic segmentation, Production of words from a given phoneme, Phonemic Synthesis, and Phonemic analysis); Phonological Working memory, Rapid naming Speed; Silent reading; Reading of words and non-words; and Auditory Comprehension of sentences from pictures. A total of 149 children, aged from 6 years to 6 and 11, of both genders who were enrolled in the 1st grade of elementary public schools were submitted to the screening protocol. Principal Component Analysis revealed four factors, accounting for $64.45 \%$ of the variance of the Protocol variables: first factor ("pre-reading"), second factor ("decoding"), third factor ("Reading"), and fourth factor "Auditory processing." The factors found corroborate those reported in the National and International literature and have been described as early signs of dyslexia and reading problems.

Keywords: reading, dyslexia, early identification, phonological awareness, assessment

\section{INTRODUCTION}

Early identification of students at risk for dyslexia has been an educational challenge in the past years. Although scientific research has explored the nature, etiology, assessment, and intervention of this learning disorder, educators are still having a hard time recognizing its signs, which suggest that a child might be at risk for reading failure without being identified. Such early identification should allow interventions to be implemented before a downward spiral of underachievement, lowered self-esteem and poor motivation sets in (Shaywitz and Shaywitz, 2005; Kirby et al., 2010; Snowling, 2013; Hulme et al., 2015). In Brazil, this topic is still fairly new; research has been carried out since 2009 (Capellini et al., 2009, 2015; Andrade et al., 2011; Fadini and Capellini, 2011; 
Fukuda and Capellini, 2011, 2012), attempting to develop a screening protocol for early identification of children at risk for dyslexia. These studies have reported that phonological awareness, verbal working memory, and rapid naming correspond to the central phonological mechanisms of acquiring reading and writing that have been also reported by De Jong and Van der Leij (1999). However, none of them explored the predictive values of each variable and their impacts on the development of a minimal protocol for early identification. Hulme and Snowling (2014) have considered letter knowledge, phonological awareness, and rapid automatized naming as predictors which are important, since it makes it possible to differentiate individual performance in students at risk for dyslexia, regarding decoding skills in alphabetic languages in the early stages. Studies have reported that students with developmental dyslexia may present as manifestations difficulties with accurate or fluent word recognition and spelling, even when they had received adequate instruction, and have no signs of fails in intelligence and sensory abilities (Shaywitz and Shaywitz, 2005; Kirby et al., 2010; Snowling, 2013; Hulme et al., 2015). The authors also described that dyslexia is the result of several risk factors, and children who have language difficulties in the first school years are usually considered as being at high risk for learning disabilities. Another important issue about dyslexia refers about family history, which also plays an important role as a predictor of literacy outcome in the preschool years. However, assessment's protocols will only help to identify the risk after the children start literacy at school, when they will have formal instruction about letter knowledge, phonological awareness, and rapid automatized naming (RAN); together these skills provide good sensitivity and specificity as a screening battery. Furthermore, the consensus between these studies is that the first signs of dyslexia include delays in speech and language development, with phonological memory (non-word repetition) and expressive language (naming) skills being particularly affected, as mentioned in the studies of Carroll et al. (2014) and Thompson et al. (2015).

The relationship between phonological awareness, rapid naming, and reading in alphabetic languages has been documented in the literature over the last decades. Germano et al. (2014) described that Brazilian Portuguese language has an alphabetic system and that most words can be successfully read through phonological decoding, according to graphemephoneme correspondences (Pinheiro et al., 2008). Scliar-Cabral (2003) described that reading in Brazilian Portuguese is considerate to be transparent since it presents a set of one-to-one graph phonological relations, that is, univocal relations, and a set of inconsistent relations, many of which are governed by rules. Thus, a characteristic of reading processing in Brazilian Portuguese is that it can be performed, almost successfully, only when the grapheme-phoneme matching rules are known and phonological decoding is used, mostly at the beginning of literacy acquisition. With regard to writing, spelling of Brazilian Portuguese is considered as being more opaque. The reason is because, in general, writing is considered a more complex cognitive process that requires intention, selection, planning, monitoring, and revision, as well as a specific coding process
(Godoy and Pinheiro, 2013). Therefore, learning to read and write implies a deliberate reflection of speech, promoting metalinguistic awareness (Bradley and Bryant, 1983; Hayes and Slater, 2008; Manz et al., 2010). Learning to read requires highly complex task, such as visual integration, orthographic, phonological, and semantic information. For example, in the dual route model of reading aloud (Coltheart et al., 2001; Ziegler et al., 2008), the reading process also requires a series of interacting stages, from letter feature detection to phonological output processes. This process was divided into two major routes: the lexical orthographic route and the non-lexical phonological route. The lexical route is important because allows the correct pronunciation of irregular words, while the non-lexical route allows the pronunciation of novel words and non-words, using not only phonological processes but also letter perception. The reading circuit is composed of neural systems including phonology, morphology, syntax, and semantics, as well as other processes such as visual and orthographic processes, that requires memory, attention, comprehension, eye movements, and cognition. By having these skills, the reader develops the so-called automatism, reading with adequate precision and speed. When this process becomes automatic, the effort toward the act of reading becomes less apparent (Norton and Wolf, 2012). Despite the vast international literature on this theme, there is lack of research on these precursors in Brazilian Portuguese Language, concerning first graders. In Brazilian Portuguese language, most words can be successfully read using phonological decoding, and even reading fluency reflect the ability of the reader to use grapheme-phoneme correspondences (Pinheiro et al., 2008). In Brazilian Portuguese, beginner readers, from first to third graders predominates the use of phonological route, but with age, performance gradually relies lexical route, such as knowledge and sight word vocabulary (Oliveira and Capellini, 2010; Mota et al., 2012). Phonological awareness is one of the most important precursor skill of reading and spelling and also one important predictors of the word recognition difficulties that characterize developmental dyslexia, one of the most common learning disorders, as reported in Peterson and Pennington (2012) and Skeide et al. (2015). Phonological awareness is the ability to identify, distinguish, and manipulate sounds within spoken language, and its importance to reading is widely acknowledged; thus, children who are able to identify and manipulate individual sounds have good academic performance. Impairment to the availability of early phonological skills can hinder subsequent reading progress (Duncan et al., 2013).

Studies have reported that the development of phonological awareness skills occurs in a sequential pattern, beginning in the 1st months of a child's life, before entering school. However, these skills have been described to have an important role in reading acquisition, as the perception that speech has an underlying phonemic structure allows storage in long-term phonological memory, using the generative mechanism of phonological memory, which converts spellings into phonology (Chard and Dickson, 1999; Cervera-Mérida and Ygual-fernández, 2003; Gombert, 2003; Hayes and Slater, 2008; Germano and Capellini, 2011). Along with phonological awareness, phonological memory or verbal short-term memory (capacity of temporary storage 
based on sound information) has been highlighted as a component of phonological processing, that is required in reading development (Wagner and Torgesen, 1987; Gathercole et al., 1999; Alloway et al., 2005). Thus, phonological memory has an important role for vocabulary acquisition, because it provides a temporary phonological representation of unfamiliar words, and later it will be responsible for an enduring representation in long-term memory (Gathercole and Baddeley, 1989; De Jong and Olson, 2004). It also contributes to the acquisition of letter knowledge (De Jong and Olson, 2004), facilitating the word identification when grapheme-phoneme correspondence rules is necessary, and facilitates text comprehension because allows children to recuperate words they have already read.

Hulme et al. (2015) have reported that the development of reading skills requires underlying ability of oral language abilities. Phonological skills has a causal influence on the later development of early word-level literacy skills, which has an impact in reading-comprehension, involving (semantic and syntactic) language skills. The authors presented a longitudinal study comparing children at familial risk for dyslexia, children with preschool language difficulties, and typically developing control children. Theirs findings described that as preschool measures of oral language it was found that phoneme awareness and grapheme-phoneme knowledge were important to acquire before school entry, which in turn predicted word-level literacy skills shortly after school entry. These results were indicated also for both typically developing children and those at risk of literacy difficulties. The authors highlighted the importance of oral language skills for the development of both word-level literacy and reading comprehension.

In addition, less speed in naming may reflect difficulty in the integration of cognitive and linguistic processes involved in fluent reading (Araújo et al., 2016). Studies (Jones et al., 2010; Araújo et al., 2016) using the Rapid Automatized Naming Test (RAN) (Denckla and Rudel, 1976), which was designed to measure the speed at which a series of highly familiar items such as letters, digits, objects, and colors can be named. As a cognitive requirement, visual naming represents a demanding array of attentional, perceptual, conceptual, memory, lexical, and articulatory processes. Wolf et al. (2000) argued that this, in turn, RAN has played an important rule for identification or recognition processes, which integrate information of present stimulus with known mental representations, quality that will influence the speed of processing. Lexical processes, that include semantic, phonological access and retrieval processes, can be integrated with cumulative information. After the cognitive processes, motor commands translate this phonological information into an articulated name. The entire process occurs within $500 \mathrm{~ms}$. Difficulties have been found to be invariant across languages (Brizzolara et al., 2006; Capellini and Conrado, 2009; Araújo et al., 2010). One of the reasons for using naming speed as part of reading evaluations is because naming speed and reading are similar. According to Kirby et al. (2010), in both RAN and oral reading subjects are solicited to move their eyes sequentially across the page, encode the stimulus that they are focusing on, access the mental representation of that stimulus, and then activate the associated motor commands that allows the subject to name that stimulus. Before the first motor commands is completed, the eyes must move on to the next stimulus, and so on. Just as in reading, the eyes must make a sweep back to the beginning of the next line. Several studies have justified the relationship between word reading and RAN concerning phonological deficits or phonological processing (Morris et al., 1998; Vaessen et al., 2009).

According to Thompson et al. (2015), identifying children with dyslexia or at risk for dyslexia means assessing the probability that a group of variables will identify positive cases of dyslexia (sensitivity), aiming to avoid false positives (specificity). Thus, the present study discusses the hypothesis that precursors of dyslexia described in Brazilian and international literature, such as knowledge of the alphabet, phonological awareness, working memory, rapid automatic naming, visual attention, reading words, and non-words, could be addressed for early identification of first grade children at risk for dyslexia in Brazil. This research had two main goals. First, we aimed to develop a screening protocol for early identification of children at risk for dyslexia; second, we aimed to identify the predictive variables of this protocol using Principal Component Analysis.

\section{MATERIALS AND METHODS}

In the first part of this study, the steps to develop this screening protocol, such as variable selection, will be described based on the literature. This screening protocol was developed to be used as a universal screening for first grade children and as part of the Tier 1 of the response to intervention (RTI) model. According to Johnston and Kirby (2006), Tier 1 aims to identify the risks for behavioral and learning problems using procedures based on the academic curriculum of these children; therefore, it would be possible to verify if these children reached the expected results at their grade level. Capellini et al. (2015) used the Screening Protocol for the Early Identification of Reading Problems in Brazilian children at risk for dyslexia as part of a RTI study. Of the 156 students that were evaluated by these authors using the protocol, 62 fulfilled the risk criteria (performance below the 25 th percentile for at least $51 \%$ of the Protocol variables). The students were submitted to phonological intervention, and the results obtained in the post-tests indicated that 12 students continued to be at risk, according to their performance. These students underwent a multidisciplinary evaluation to confirm the diagnosis.

Because reading involves multiple linguistic, visual, and attentional processes, it is likely that variable patterns of weaknesses may contribute to reading difficulties among children, as mentioned by Norton and Wolf (2012). However, the present study considered the recent investigations that have demonstrated that dyslexic children may have difficulties in underlying processes (e.g., phonological awareness and rapid naming test) and difficulties with RAN, related to visual attention processing (Franceschini et al., 2012; Germano et al., 2014). Taking that into consideration, the development of the screening protocol for early identification of reading problems (Capellini et al., 2009, 2015, 2017) was based on a literature review to 
identify the skills for effective reading and writing. The Protocol was composed of seven cognitive-linguistic skills divided into seven tests. The tests and justification for their selection are shown in Table 1.

After selecting the tests, the next step concerned the choice of linguistic stimuli to compose the Protocol. This study was based on a phonological perspective called linear model and on the hierarchical model (Câmera, 1970a,b; Selkirk, 1982). The screening protocol was composed of words from a word bank created for this study; these words were extracted from 1th to 5 th grade textbooks (elementary school) written in Portuguese (Germano and Capellini, 2008; Germano, 2011). This word bank included words belonging to different word classes or parts of speech, such as pronouns, prepositions, adjectives, adverbs, verbs, and nouns. Exclusion criteria were as follows: pronouns, prepositions, words that could vary according to the class or grammatical category, gender, and agreement, which happens when a word changes form depending on the other words to which it relates (e.g., adjectives, adverbs, verbs). In addition, as linguistic criteria (Brazilian Portuguese Language), words that had one of the following characteristics were excluded: (1) Syllable reduction (for example, the word "fósforo" (phosphorus) pronounced as [fósfuru] [ fosfru]. (2) Open and close vowels (for example, the word "bolacha" (cookie) pronounced as [ô] and "bola" (ball) pronounced as [ó]). (3) Words with diphthong and hiatus [for example, the word "vaidade" (vainity) can be pronounced as "vai.da.de," "va.i.da.de"] and/or monotongation [for example, the word "caixa" (box) can be pronounced as c[aj]xa, c[a]xa]. (4) Words with nasal vowels [for example, "orgão" (organ), "homem" (man)]. (5) Tonicity of syllables containing vowel sounds (word selection was made based on the stressed syllable position, and the stressed syllable was in the same position in the target word and in word in the correct answer. (6) Neutralization [e.g., the word "pepino" (cucumber) can be pronounced as "p[e]pino" or "p[i]pino"]. (7) Consonant vocalization (e.g., the pronunciation of words with a consonant corresponding to a post-vowel velar phoneme/l/ may change, and thus it can be pronounced as $/ \mathrm{u} /$ or $/ \mathrm{w} /$ ). Most of the words used in Brazilian Portuguese had simple syllable structure, such as consonant-vowel, consonant-vowel-consonant, consonantconsonant-vowel. The screening protocol developed was applied to first graders.

The second goal of this study was to identify the predictive variables of this protocol using Principal Component Analysis. This study was approved by the Research Ethics Committee of the University Júlio de Mesquita Filho (FFC/UNESP, São Paulo State University - School of Philosophy and Sciences), Protocol No. 0663/2013.

\section{Participants}

A total of 149 children, aged from 6 years to 6 years and 11 months, of both genders, who were enrolled in the 1 st grade of elementary public schools participated in this study. Parents and/or guardians of all the participants signed an informed consent form. Exclusion criteria for participation in the study were as follows: children with sensory, motor, or cognitive impairment and children whose parents/guardians did not sign the Informed Consent form; inclusion criteria: children whose parents/guardians signed the Informed Consent form and children without sensory, motor, or cognitive impairment, according to information in the school records. Two schools with similar socio-economic status and high rating level in the Secretaria da Educação do Estado de São Paulo (2014) (System of Evaluation of School Performance of the State of São Paulo) participated in this study.

\section{Procedures}

All participants were submitted to the Screening Protocol for Early Identification of Reading Problems (Capellini et al., 2015). The protocol was applied individually in a 50 -min session. The protocol was composed of seven cognitive-linguistic tests. Each test was composed of two training trials and test stimuli. The training trials were not scored. During the training trials, the children were informed that the Examiner could offer further explanation about what was being asked and that the Examiner could repeat the stimulus, if necessary. During the test, the Examiner explained that the stimulus could be repeated only once. The rating scale values for Punctuation were: "one" for a correct answer and "zero" for an incorrect answer or a blank. Children marked their answers on an Answer Sheet. The screening protocol was composed of the following tests:

(1) Letter-naming test. Letters of the alphabet were presented randomly to the children, and they were asked to name the letter shown. Children were presented with visual stimuli with 12 pt Arial uppercase letters. A total of 23 stimuli were shown.

(2) Test of phonological awareness. Stimuli were orally presented without visual cues. This test was composed of the following subtests:

(2.1) Subtest of Rhyme Production. The Examiner presented a word, and the student was asked to say a word that ended with the same sound. This subtest comprised 20 words (target stimuli). Example: target word: "cola" (glue) and expected answer: "bola" (ball).

(2.2) Subtest of Rhyme Identification. The Examiner presented a series of three words, and the student was asked to provide a pair of rhyming words (words that sound the same at the end). Twenty groups of three words were presented. Example: a series of three words, "milho" (corn), "baleia" (whale), and "filho" (son). Expected answer: "milho/ filho."

(2.3) Subtest of Syllabic Segmentation. Students were presented with twenty-one words one at a time. The words were selected according to number of syllables (from 2 to 4 syllables), and the children were asked to dived them into syllables. Example: target stimulus: "vaca" (cow). Expected answer: "va - ca."

(2.4) Subtest of Production of words from a given phoneme. A sound/phoneme of the alphabet was presented to the students, and they were asked to say a word beginning with the same sound. Example: target stimulus: phoneme /a/. Expected answer: "asa” (wing). 
TABLE 1 | List of variables and justification for the development of the screening protocol for early identification of children at risk for dyslexia (Capellini et al., 2017).

Tests of the screening protocol

(1) Letter-naming

(2) Phonological Awareness: composed by the subtests

(2.1) Rhyme production

(2.2) Rhyme identification

(2.3) Syllabic segmentation

(2.4) Production of words from a given phoneme

(2.5) Phonemic synthesis

(2.6) Phonemic analysis

(3) Phonological working memory (repetition of words and non-words)

(4) Rapid naming speed

(5) Silent reading

(6) Reading words and non-words

(7) Auditory comprehension of sentences from picture.

\section{Justification for test selection}

Pennington and Lefly (2001) stated that Letter-name knowledge is at the intersection between spoken and written language because letters are the written representations of phonemes or combinations of phonemes. It is plausible that the ability to learn letter names depends on underlying phonological development. As pointed out by Share (1995), letter names are, after all, non-words and the ability to repeat and remember non-words.

As reported by Brunswick et al. (2012), whereas awareness of larger phonological units, such as the syllable and onset-rime, develop independently of reading instruction in 3-to 5-year-olds (Bradley and Bryant, 1983; Badian, 2001; Gipstein et al., 2001), awareness of smaller units of sound, such as the phoneme, usually develop later as a result of reading development (De Jong and van der Leij, 1999; Cardoso-Martins and Pennington, 2004; Ziegler and Goswami, 2006).

Articulatory loop (phonological working memory system) is thought to be responsible for the temporary storage of verbal information, while other cognitive tasks, such as verbal reasoning or auditory and reading comprehension, are performed (Baddeley, 1986). The task of repeating single non-words is particularly appropriate for use with young children. Throughout the course of childhood, the child, who seems to be innately equipped with both, desire and facility to learn new words, encounters many thousands of unfamiliar words. Exposure to unfamiliar phonological forms is a natural and common occurrence for the child. A further issue of interest is whether non-word repetition ability shares a developmental link with reading achievement. Previously reviewed findings indicate that such a relationship might well exist. Impaired non-word repetition skills have consistently been shown to be characteristic of poor readers and children classified as dyslexic, as described by Gathercole et al. (1994)

According with Jones et al. (2010), naming-speed on these tasks is proposed to assess low-level factors involved in reading fluency, such as: attention to the stimulus bi-hemispheric visual processes responsible for feature detection; matching of feature and pattern encoding to stored orthographic representations; integration of visual and phonological information; and motor activation leading to articulation. Non-alphanumeric stimuli are preferred for use with young students or those who may not have learned letters and digits well enough to be "highly familiar" with them (Wolf and Bowers, 1999; Jones et al., 2010; Kirby et al., 2010).

Measures of silent reading typically include a decision component, such as semantic categorization, sentence verification, or lexical decision. In addition, the main goal in silent reading is to comprehend and assimilate the meaning of the text, which relies on the grapheme-to-semantic decoding in the lexical route (Galin et al., 1992; van den Boer et al., 2014; Zhao et al., 2016). This protocol was based on semantic categorization via lexical processing. Whereas phonological representations might be activated in both silent and oral reading, computation of a phonetic code is specific to oral reading (van den Boer et al., 2014).

Given the nature of the written language, in order to learn to read, the beginning reader needs to decode the written words into speech units and then comprehend the words (and sentences/discourse) to derive meaning, according to The Simple View of Reading (Gough and Tunmer, 1986; Hoover and Gough, 1990). According to this view, reading is composed of word recognition and language comprehension. Word recognition is the translation of print into language (i.e., sounds and words) and comprehension is the making sense of language (Rack et al., 1992; Catts and Hogan, 2003). Moreover, word recognition is a good predictor of reading comprehension performance in children at the beginning of reading acquisition (Chaves-Sousa et al., 2016).

Montgomery (1995) argued that sentence comprehension requires that previous information be stored temporarily while new, incoming information is processed. Clark and Clark (1977) have proposed that phonological memory is critical to comprehension because listeners presumably store entire sentences in a phonological input store until all syntactic and semantic analyses have been completed.
(2.5) Subtest of Phonemic Synthesis. Twenty-one words were presented one at time to the students. The Examiner pronounced each phoneme of the word and asked the children to combine them forming a word. The words were selected according to the number of syllables (from 2 to 4 syllables). Example, target stimuli: /k/ /a/ /f/ $\varepsilon /$. Expected answer: "café"/ coffee.

(2.6) Subtest of Phonemic analysis. Twenty-one words were presented one at time to the students. The Examiner pronounced the words and asked the children to divide them by pronouncing each phoneme/sound of each word. The words were selected according to the number of syllables (from 2 to 4 syllables). Example, target stimulus: "bola/ ball." Expected answer: /b/ /ó/ /l/ /a/.

(2.7) Subtest of Identification of the initial sound/phoneme. Twenty-one words were presented one at time to the students. The Examiner pronounced a word and asked the children to say the initial sound/phoneme of the word out loud. Example, target stimulus: "boca/mouth." Expected answer: /b/. 
(3) Subtest of Phonological Working memory. Twenty-four non-words were presented one at time to the students, and they were asked to repeat the words as they heard them. Repetition was allowed only once. The non-words varied in length (from 1 to 6 syllables).

(4) Test of Rapid Naming Speed using pictures. Children were presented with flashcards containing seven lines and five columns with colorful picture images: car, ball, duck, house, and key. First, the students were asked to identify each picture stimulus, aiming to verify their recognition. Afterward, they were instructed to say the name of each stimulus as quickly as possible. The examiner used a chronometer to record the time.

(5) Silent reading. Students were presented with 10 colored pictures, below which there were two words, and they were asked to identify the word that described the picture. The words in the picture belonged to different semantic categories.

(6) Reading of words and non-words. A list with 20 words and 20 non-words was presented to the students, and they were asked to read them aloud. Children were presented with visual stimuli with $12 \mathrm{pt}$ Arial uppercase letters. A total of 23 stimuli were shown.

(7) Auditory Comprehension of sentences from pictures. Twenty incomplete sentences with illustrations or figures were presented to the students. The sentences with a missing part were orally presented by the examiner. The children should listen to the sentence and name the missing part, according to the picture.

\section{RESULTS}

Statistical analysis was carried out using the SPSS (Statistical Package for Social Sciences), version 23.0. Some descriptive statistics are shown in Table 2.

Principal Components Analysis (PCA) was carried out to reduce the set of Protocol variables before determining the number of variables that could contribute to the early identification of children with dyslexia, such as skills that are predictors of reading acquisition (Table 3); Rotation Method used: Varimax with Kaiser Normalization. All factor loadings greater than or equal to 1.00 were used for interpretation.

Although 13 components were retained (factors), only 4 accounted for $64.45 \%$ of the total variance (eigenvalues $>1$ ). There was a slight change in all variables due to varimax rotation. Analyzing each factor individually, it was found that the first factor explained $32.56 \%$ of variance with no rotation with no rotation and $23.25 \%$ with rotation. The second factor explained $16.06 \%$ with no rotation and $15.55 \%$ with rotation. The third factor explained $8.05 \%$ with no rotation and $14.52 \%$ with rotation, and the fourth factor explained $7.77 \%$ with no rotation and $11.10 \%$ with rotation. In order to clearly define the groups of variables, a correlation matrix was created employing varimax rotation (a more conservative approach) (Table 4).
The first factor, called "pre-reading" had high loadings for five variables, indicating $23.26 \%$ of variance for all 13 Protocol variables. The variables Letter-naming $(M=21.66 / S D=2.88)$ and Rhyme production $(M=11.42 / S D=6.96)$ had the same loading factor, followed by the variables Rhyme identification, Production of words from a given phoneme, and Identification of the initial phoneme. Letter-naming is one of the most important findings referred to as the foundation of other skills in the first school years, when additional skills are developed. This variable has been proved to be influenced by family environment and pre-school literacy instruction. It can be observed the standard deviation of this variable was low for all students. Moreover, Letter-naming has been associated with phonological awareness because most letter names contain clues regarding their corresponding sound. Rhyme Production $(M=11.42 / S D=6.96)$ and Rhyme identification $(M=15.45 / S D=5.09)$ allow students to realize that words can share identical sound segments, as the perception of greater amounts of sounds will facilitate the formation and increase of lexical and semantic memories, which will be accessed to retrieve auditory information and reading comprehension, afterward. Studies have pointed out that the acquisition of rhymes can occur before literacy instruction, around 3 years old, and it can be combined with skills related to the identification of the initial phonemes, contributing to foster phonemic awareness. Thus, phonemic awareness can emerge as the perception of the smaller segments of spoken words (phonemes), allowing children to perform tasks such as production of words from a given phoneme $(M=14.23 / S D=8.25)$ and identify of the initial phoneme $(M=15.45 / S D=5.09)$, as well to start establishing phoneme-grapheme correspondence, which is important for reading acquisition. The larger standard deviation of these tests suggests that some of the students evaluated may have had difficulties in accessing a word or a phoneme.

The second factor was called "decoding" since it refers to the ability of using grapheme-phoneme correspondences required to read words. It had four variables with $15.56 \%$ of variance. The variable Phonemic analysis had the highest factor loadings, followed by the loadings of positive sign of the variables Phonemic Synthesis and Reading words and non-words and the loading of negative sign of the variable Rapid Naming Speed using pictures, which had negative correlation with the second component. In the RAN test, the naming time is measured and the score is expressed in seconds. Lower scores indicate better performance on the test. The ability to identify phonemes contributes to alphabet comprehension since a phoneme may be represented by a sequence of letters. However, it is important to highlight that the Brazilian Teaching Method does not emphasize teaching letter-sound correspondence. Therefore, it can be said that with regard to the Phonemic Analysis $(M=2.76 / S D=5.66)$ and Phonemic Synthesis $(M=2.72 / S D=4.84)$, the students had low performance, suggesting that these variables are important predictors for early identification of dyslexia for this Protocol. These performance difficulties also influenced the students' performance in the Naming Speed Task $(M=43.44 / S D=10.63)$ 
TABLE 2 | Distribution of mean (M), standard deviation (SD), minimum (min), and maximum values (max), and students' test scores at the 25th and 75th percentiles using the proposed protocol.

\begin{tabular}{|c|c|c|c|c|c|c|c|c|}
\hline Tests & $N$ & Minimum & Maximum & M6 & $S D$ & $25 \%$ & Median & $75 \%$ \\
\hline LN (/23) & 149 & 5.00 & 23.00 & 21.66 & 2.88 & 21.00 & 23.00 & 23.00 \\
\hline $\mathrm{RP}(20)$ & 149 & 0.00 & 20.00 & 11.42 & 6.96 & 5.00 & 13.00 & 18.00 \\
\hline $\mathrm{RI}(/ 20)$ & 149 & 0.00 & 20.00 & 15.45 & 5.09 & 12.50 & 18.00 & 19.00 \\
\hline SS (/21) & 149 & 0.00 & 21.00 & 19.38 & 3.41 & 19.00 & 21.00 & 21.00 \\
\hline PWPh (/21) & 149 & 0.00 & 22.00 & 18.68 & 3.53 & 18.00 & 20.00 & 21.00 \\
\hline $\mathrm{PhS}(/ 21)$ & 149 & 0.00 & 21.00 & 2.76 & 5.66 & 0.00 & 0.00 & 1.00 \\
\hline $\mathrm{PhA}(/ 21)$ & 149 & 0.00 & 20.00 & 2.72 & 4.84 & 0.00 & 0.00 & 4.00 \\
\hline $\mathrm{IPh}(/ 21)$ & 149 & 0.00 & 21.00 & 14.23 & 8.25 & 5.00 & 20.00 & 21.00 \\
\hline WM (/24) & 149 & 1.00 & 24.00 & 20.54 & 3.05 & 19.50 & 21.00 & 23.00 \\
\hline RAN (seconds) & 149 & 20.00 & 80.00 & 43.44 & 10.63 & 35.00 & 42.00 & 51.00 \\
\hline $\mathrm{SR}(/ 10)$ & 149 & 2.00 & 10.00 & 8.95 & 1.52 & 8.00 & 10.00 & 10.00 \\
\hline RWNW (/40) & 149 & 0.00 & 40.00 & 17.15 & 16.08 & 0.00 & 16.00 & 34.00 \\
\hline $\mathrm{AC}(/ 20)$ & 149 & 0.00 & 28.00 & 19.32 & 2.51 & 19.00 & 20.00 & 20.00 \\
\hline
\end{tabular}

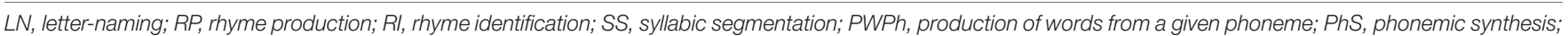

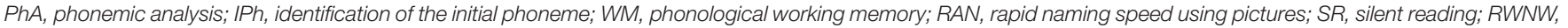
reading of words and non-words; AC, auditory comprehension of sentences from pictures.

TABLE 3 | Principal component analysis with extraction sums of squared loadings and rotation sums of squared loadings (Varimax).

\begin{tabular}{|c|c|c|c|c|c|c|c|c|c|}
\hline \multirow[b]{2}{*}{ Factor } & \multicolumn{3}{|c|}{ Initial eigenvalues } & \multicolumn{3}{|c|}{ Extraction sums of squared loadings } & \multicolumn{3}{|c|}{ Rotation sums of squared loadings } \\
\hline & Total & $\begin{array}{c}\% \text { of } \\
\text { Variance }\end{array}$ & $\begin{array}{c}\text { Cumulative } \\
\%\end{array}$ & Total & $\begin{array}{c}\% \text { of } \\
\text { Variance }\end{array}$ & $\begin{array}{c}\text { Cumulative } \\
\%\end{array}$ & Total & $\begin{array}{c}\% \text { of } \\
\text { Variance }\end{array}$ & $\begin{array}{c}\text { Cumulative } \\
\%\end{array}$ \\
\hline 1 & 4.233 & 32.564 & 32.564 & 4.233 & 32.564 & 32.564 & 3.024 & 23.259 & 23.259 \\
\hline 2 & 2.089 & 16.069 & 48.632 & 2.089 & 16.069 & 48.632 & 2.023 & 15.565 & 38.824 \\
\hline 3 & 1.047 & 8.053 & 56.685 & 1.047 & 8.053 & 56.685 & 1.888 & 14.526 & 53.350 \\
\hline 4 & 1.010 & 7.770 & 64.455 & 1.010 & 7.770 & 64.455 & 1.444 & 11.105 & 64.455 \\
\hline 5 & 0.857 & 6.592 & 71.047 & & & & & & \\
\hline 6 & 0.746 & 5.736 & 76.782 & & & & & & \\
\hline 7 & 0.606 & 4.665 & 81.447 & & & & & & \\
\hline 8 & 0.571 & 4.394 & 85.841 & & & & & & \\
\hline 9 & 0.485 & 3.734 & 89.575 & & & & & & \\
\hline 10 & 0.427 & 3.288 & 92.863 & & & & & & \\
\hline 11 & 0.368 & 2.827 & 95.690 & & & & & & \\
\hline 12 & 0.321 & 2.472 & 98.162 & & & & & & \\
\hline 13 & 0.239 & 1.838 & 100.000 & & & & & & \\
\hline
\end{tabular}

since slow processing speed indicates that the student had difficulties in combining visual with phonological information, suggesting difficulties in reading words and non-words $(M=17.15 / S D=16.08)$.

The third factor, called "Reading" had only two variables accounting for $14.56 \%$ of variance. Syllabic segmentation $(M=19.38 / S D=3.41)$ and Silent reading $(M=8.95 / S D=1.52)$ had higher factor loadings. Results indicated that the students had good performance in the Syllabic segmentation test, which does not depend on explicit instruction, and even preschoolers or illiterates have these skills. Silent reading test was the other variable correlated with this factor, which is a specific task that compares recognition between two words and that can be performed by readers without explicit syllable decodification, and the syllables may act as perceptual units in word recognition because of their phonological and orthographic properties, as mentioned by Ashby (2016). Finally, the fourth factor was called "Auditory processing" and comprised the two last variables, accounting for $11.10 \%$ of variance and $64.45 \%$ of cumulative variance. Auditory Comprehension of sentences from picture $(M=19.32 / S D=2.51)$ and the Phonological Working memory $(M=20.54 / S D=3.05)$ comprise the last factor. These two variables are somehow correlated because the first one requires that previous information be temporarily stored in the phonological memory (phonological input store until all syntactic and semantic analyses have been completed). Table 5 shows the distribution of factors, according to the risk criteria performance below the 25 th percentile and at least $51 \%$ of the variables correlated with the factors represented by total variance explained by each factor. It can be seen from Table 5 that 34 students were identified by the first factor, 87 students by the second factor, 19 by the third factor, and 16 by the fourth factor. 
TABLE 4 | Rotated factor loadings in PCA for the four components.

\begin{tabular}{lcccc}
\hline Variable & $\begin{array}{c}\text { Pre- } \\
\text { reading }\end{array}$ & Decoding & Reading & $\begin{array}{c}\text { Auditory } \\
\text { processing }\end{array}$ \\
\hline LN (/23) & $\mathbf{0 . 7 6 9 ^ { * }}$ & 0.177 & 0.134 & -0.226 \\
RP (20) & $\mathbf{0 . 7 6 9 *}$ & 0.000 & 0.060 & 0.254 \\
RI (/20) & $\mathbf{0 . 7 5 6 ^ { * }}$ & 0.076 & 0.172 & 0.239 \\
SS (/21) & 0.101 & -0.064 & $\mathbf{0 . 8 1 5 ^ { * }}$ & 0.259 \\
PWPh (/21) & $\mathbf{0 . 7 2 2 *}$ & 0.261 & 0.128 & 0.002 \\
PhS (/21) & 0.268 & $\mathbf{0 . 5 1 5 *}$ & 0.014 & 0.408 \\
PhA (/21) & 0.067 & $\mathbf{0 . 8 5 6 *}$ & -0.005 & 0.140 \\
IPh (/21) & $\mathbf{0 . 6 8 7 ^ { * }}$ & -0.123 & -0.012 & 0.444 \\
WM (/24) & 0.367 & 0.192 & 0.447 & $\mathbf{0 . 4 7 0 *}$ \\
RAN (seconds) & -0.125 & $-\mathbf{0 . 5 6 4 *}$ & -0.452 & 0.181 \\
SR (/10) & 0.172 & 0.339 & $\mathbf{0 . 7 0 3 *}$ & -0.177 \\
RWNW (/40) & 0.018 & $\mathbf{0 . 6 5 7 ^ { * }}$ & 0.507 & -0.100 \\
AC (/20) & 0.092 & 0.027 & 0.003 & $\mathbf{0 . 7 2 4 *}$ \\
\hline
\end{tabular}

LN, letter-naming; RP, rhyme production; Rl, rhyme identification; SS, syllabic segmentation; PWPh, production of words from a given phoneme; PhS, phonemic synthesis; PhA, phonemic analysis; IPh, identification of the initial phoneme; WM, phonological working memory; RAN, rapid naming speed using pictures; $S R$, silent reading; RWNW, reading of words and non-words; AC, auditory comprehension of sentences from picture. ${ }^{*} p<0.05$.

\section{DISCUSSION}

This research presented two studies. In study 1 , the results indicated that it was possible to develop a screening protocol for early identification of children at risk for dyslexia in firstgrade students, using Brazilian Portuguese stimuli. As for Study 2, Principal Component Analysis revealed four factors accounting for $64.45 \%$ variance in all Protocol variables. These factors are consistent with those reported in the National and International literature, and they have been associated with early signs of dyslexia.

Learning how to read in alphabetic systems require the acquisition and domain of associates each distinctive element of visual symbols onto units of sound (phonology). This correspondence process is called phonological recoding (Share, 1995). Nevertheless, this mapping process is influenced by inconsistency in the symbol-to-sound mapping of orthographies. For example, in some Languages it's possible to notice that one letter or letter cluster can be associated with several sound pronunciations (e.g., English, Danish), whereas in other Languages, such as Italian and Spanish, there is a one-toone correspondence (one letter per sound). However, in some Languages, such as Portuguese and French, it is possible to find both irregularities and regularities, affecting recoding accuracy, which is in line with the reduced consistency of these languages (Ziegler and Goswami, 2006).

The first factor found was denominated "pre-reading" because its variables can be observed before formal education. The "prereading" factor comprised the following tests: Letter-naming, Rhyme Production, Rhyme identification, Production of words from a given phoneme, and Identification of the initial phoneme. Letter naming has been considered as a major indicator because its possibility the association between a letter and sound (letterto-speech sound integration), which can be impaired in children with dyslexia. Although letter naming is considered to be one of the most important predictors of succeeding reading acquisition. However, it's important to note that it is strongly influenced by others factors, such as verbal abilities, teaching methods, and parental input. Letter naming is also closely correlated

TABLE 5 | Distribution of the factors according to the risk criteria (performance below the 25th percentile).

\begin{tabular}{|c|c|c|c|c|c|c|c|}
\hline Factors & Tests & $n$ & $\begin{array}{c}n \\
\text { (risk criteria }<25 \%)\end{array}$ & Minimum & Maximum & $M$ & $S D$ \\
\hline \multirow[t]{4}{*}{ Pre-reading } & LN (/23) & 149 & 36 & 5 & 23 & 21.66 & 2.88 \\
\hline & RI (/20) & 149 & 35 & 0 & 20 & 15.45 & 5.09 \\
\hline & PWPh (/21) & 149 & 44 & 0 & 22 & 18.68 & 3.53 \\
\hline & $\mathrm{IPh}(/ 21)$ & 149 & 43 & 0 & 21 & 14.23 & 8.25 \\
\hline \multirow[t]{5}{*}{ Decoding } & $\mathrm{PhS}(/ 21)$ & 149 & 108 & 0 & 21 & 2.76 & 5.66 \\
\hline & $\mathrm{PhA}(/ 21)$ & 149 & 84 & 0 & 20 & 2.72 & 4.84 \\
\hline & RAN (seconds) & 149 & 145 & 20 & 80 & 43.44 & 10.63 \\
\hline & RWNW (/40) & 149 & 75 & 0 & 40 & 17.15 & 16.08 \\
\hline & Total & & 87 & & & & \\
\hline Reading & $\mathrm{SR}(/ 10)$ & 149 & 39 & 2 & 10 & 8.95 & 1.52 \\
\hline & $\mathrm{AC}(/ 20)$ & 149 & 35 & 0 & 28 & 19.32 & 2.51 \\
\hline & Total & & 16 & & & & \\
\hline
\end{tabular}

LN, letter-naming; RP, rhyme production; RI, rhyme identification; SS, syllabic segmentation; PWPh, production of words from a given phoneme; PhS, phonemic synthesis; PhA, phonemic analysis; IPh, identification of the initial phoneme; WM, phonological working memory; RAN, rapid naming speed using pictures; SR, silent reading; RWNW, reading of words and non-words; AC, auditory comprehension of sentences from picture. 
with phonological awareness (Lerner and Lonigan, 2016). The performance of letter knowledge and phonological awareness at kindergarten have been strongly referred as predictors for Firstgrade reading achievement. These findings were pointed even when variables, such as parental education level and teacher-rated academic competence (Ortiz et al., 2012; Lerner and Lonigan, 2016); Lerner and Lonigan (2016) also discussed the influence of phonological awareness on the acquisition of letter knowledge.

Unfortunately, even though international researchers have pointed out the role of Letter-naming and teaching of letter-naming correspondence in several alphabetic languages, according to the Parâmetros curriculares nacionais da Lingua Portuguesa (Brasil, 1997) (National curricular parameters of Portuguese Language), the current understanding of the relationship between writing acquisition and writing skills confront entrenched beliefs that the phonics instruction domain is a prerequisite for language teaching, indicating that the two learning processes (literacy and language teaching itself) could occur simultaneously. Therefore, with regard to the Alphabetic language principles, the acquisition of alphabetic knowledge does not guarantee that the student will be able to understand or produce texts in writing. Finally, according to these parameters, teaching basic units could comprise not only reading comprehension, which does not mean that teaching words or sentences would not focus on specific didactic situations that would benefit students.

Perhaps, because of this lack of systematic approach to teaching, letter-naming skills have still been considered as one of the predictors to dyslexia, as reported in international studies on alphabetic language. Kim et al. (2010) and Lerner and Lonigan (2016) argued that for letter names that incorporated important traces of the corresponding sound. Therefore, knowing the name of a letter was a strong predictor to realize if the children knows the corresponding sound. However, this can be observed in children with good developed phonological awareness skills.

According to Lonigan et al. (2009), phonological awareness develops along a continuum awareness of large and concrete sound units (i.e., words, syllables) to awareness of small and abstract sound units (i.e., phonemes). The other variables correlated with Factor 1 concern the perception of large amounts of sounds (Rhymes) and the use of phoneme knowledge. The findings of this study showed that students had more difficulties with Identification of the Initial Phoneme than with Production of words from a given phoneme. Therefore, in these phonemic tests, students have to identify the first phoneme of the words (i.e., alliteration) and retrieve another word from the phonological long-term memory. Our results corroborate with those found in the literature suggesting that even before entering preschool, children learn some basic language skills and notions (detection, rhyming, and alliteration) that will facilitate the development of reading skills based on a variety of life experiences. These experiences contribute to their acquisition of receptive vocabulary phonological skills, and narrative understanding and production (Hayes and Slater, 2008; Manz et al., 2010). With regard to Phonemic awareness, as mentioned by Silvén et al. (2002), this finding may support the assumption that conscious access to speech patterns is influenced, at least indirectly, by advances in implicit phonetic and phonotactic representations that can be related to language development during the 1st year of life. Ouellette and Haley (2013) stated that the principal motivation for considering the role of vocabulary in the emergence of phonemic awareness could be associated with the first words stored in mental lexicon. As new words are added, segmental representation becomes necessary so that similar sounding items are not confused with each other. Essentially, increased extensiveness of oral vocabulary causes restructuring, by which there are more specific phonemic-level representations. Accordingly, Law et al. (2016) evaluated a group of pre-reading children with a family risk for dyslexia. As results, the authors founded that there was an influence of phonological and morphological awareness on reading development. According to Morris et al. (2012), morphological awareness can be defined as the explicit awareness and ability to manipulate and reflect upon the morphemic structure of words, which has already been demonstrated in prereading children. The results obtained suggest that phonological awareness is a relevant component of morphological awareness, independent of reading experience. It is also important to highlight that in the present study, the variables correlated with factor 2, corroborate those reported in the study of Hulme et al. (2015), who found that children at risk for dyslexia show general deficits in oral language skills in the preschool years. Those deficits are presented in a way that a percentage of these children satisfy the criteria for language impairment diagnosis. Poor oral language skills, in turn, appear to affect the later development of decoding (through problems in acquiring letter-sound knowledge and phoneme awareness) as well as reading comprehension abilities. Based on these international studies, it can be said that the variables correlated with the first factor proved important as predictive variables in the Brazilian Portuguese Language. As an alphabetic language, difficulties in acquiring letter naming and initial phonological awareness skills can be seen as a sign of reading difficulties.

Thus, the 2nd factor was comprised the following tests: Phonemic Synthesis, Phonemic analysis, Rapid Naming Speed using pictures, and Reading of words and non-words. As described by Ouellette and Haley (2013), phonemic awareness can also be categorized based on how it is being used. Specifically, explicit awareness at the level of the phoneme includes both analytic (ability to break a word down into constituent sounds) and synthetic skills (combining sounds together to make a larger segment, such as word). Analysis tasks are more difficult than synthesis tasks. Our findings showed that phonemic analysis and phonemic synthesis had different loadings; however, the students had similar performance (mean) on the tests of phonemic analysis and phonemic synthesis. Furthermore, our findings also showed difficulties in reading words and non-words and a negative loading for Rapid Naming Speed (RAN). This suggests that difficulties in decoding skills were related with slow phonological access. Evaluating the double deficit hypothesis, Brazilian and International studies (Wolf and Bowers, 1999; Andrade et al., 2013; Silva and Capellini, 2013; De Groot et al., 2017), demonstrated the relationship among phonological awareness difficulties, dyslexia, and impaired RAN. Hulme et al. 
(2015) argued that phoneme awareness and letter knowledge are the most important predictors of early word-reading skills across several languages, and there is evidence of reciprocal interaction between them. Extending these ideas mentioned before (Shaywitz and Shaywitz, 2005; Kirby et al., 2010; Snowling, 2013; Hulme et al., 2015). Kirby et al. (2010) examined RAN effects across languages and the impact of its relationship to reading. These authors also reviewed the instructional literature aiming to improve and to use RAN as a predictor of RTI. They concluded that RAN is uniquely associated with a variety of reading tasks across orthographies, and that the use of RAN measures would be very useful for early identification.

The third factor was called "reading" and had only two variables. It was composed of the tests Syllabic segmentation and Silent reading. Syllabic segmentation is one of the skills that does not depend on explicit instruction. Our results might suggest that students had good performance on Syllabic segmentation, but they had some difficulties in the reading tests. One possible explanation is that in the test of silent reading they could use the visual or orthographic routes instead of the phonological route. Thus, the orthographic process occurs when groups of letters or entire words are processed as single units rather and not as a sequence of grapheme-phoneme correspondences, which is related to phonological processing (Ehri, 1997; Pinheiro et al., 2008; Oliveira and Capellini, 2010; Mota et al., 2012; Majerus and Cowan, 2016). Moreover, Kirby et al. (2010) stated that because of the orthographic process, it's possible to establish the mechanism of quickly recognition of very frequent or familiar (Morris et al., 1998; Vaessen et al., 2009). Since the reading test was composed of reading words and non-words, both variables correlated with factor 3 may demonstrate that simpler phonological awareness skills (e.g., Syllabic segmentation) can contribute to early identification of dyslexia because syllabic segmentation does not depend on reading instruction and is not related to oral language acquisition. The other variable, the variable related to Reading, will also contribute for early identification of dyslexia since it's enables evaluation of the reading level, considering the use of the lexical route and the phonological route. In a study addressing cross-language reading comparison, Ziegler and Goswami (2006) reported that one of the most significant findings was that the students who were acquiring reading in orthographically consistent languages (Greek, Finnish, German, Italian, and Spanish) were close to ceiling in both word and non-word reading by the middle of first grade. Unfortunately, this was not observed in the Brazilian population studied. In contrast, the standard deviation of this test for Brazilian Portuguese Language was large (students who were not able to read a single word). According to Scliar-Cabral (2003), Brazilian Portuguese is also considered to be transparent, and reading can be performed only when the grapheme-phoneme matching rules are known and phonological decoding is used, mostly at the beginning of literacy. However, it is worth highlighting that despite the existence of the National curricular parameters of Portuguese language (Brasil, 1997) there is no systematic teaching of grapheme-phoneme correspondence rules. The findings shown in Table 5 can be justified by the lack of systematic teaching, and because of this, factor 2 ("Decoding") identified a larger number of students, when compared with factors 1 , 3 , and 4. Factor 2 was composed of the Phonemic tests Rapid Naming Speed using pictures and Reading of words and nonwords.

The 4th factor comprised the tests of Auditory Comprehension of sentences from pictures and Phonological Working memory. A deficit in verbal short-term memory is well documented in dyslexia and can be observed in tasks such as reading longer pseudowords or sequences are used, specially repeating 4 to 6-syllable pseudowords that are related with phonological deficits (Ramus and Ahissar, 2012). Baddeley (1986) defined phonological memory as the coding of information, a sound-based representation system for temporary storage, that can be measured by immediate recall of verbally presented material (e.g., repetition of nonwords), as also reported by Lonigan et al. (2009). Studies (Ehri, 1997; Pinheiro et al., 2008; Oliveira and Capellini, 2010; Mota et al., 2012; Majerus and Cowan, 2016) reported that dyslexia children have difficulties in phonological awareness, and this difficulties can still be observed in adults with a history of dyslexia. This difficulty plays an important rule to characterize the dyslexia profile, suggesting that the reduction of the amount of phonological and graphemic information that can be co-activated during the reading process can influence the recoding reading process, when graphemephoneme correspondence are not yet automatized, leading to difficulties in reading comprehension. Therefore, it's important that the children have an efficient phonological memory that enable the maintenance of an accurate representation of the correspondence grapheme-phonemes while word decoding and, consequently, allocate more cognitive resources to comprehension processes. (Lonigan et al., 2009). Spokenlanguage comprehension and processing depend on the accurate isolation and interpretation of meaningful units of speech such as words, sentences, or utterances. Such highlevel perceptual units correspond to the consolidation of basal acoustic-phonetic cues that can be categorized within various time scales corresponding to various phonological grain size units. Therefore, in order to have a good performance in Auditory Comprehension of sentences from pictures, the students evaluated were able to decode phonological information.

Finally, it is possible to identify the variables for the Screening Protocol for Early Identification of Reading Problems in Brazilian children enrolled in first grade, according to the order of the predictive value of each variable, which was as follows: Letternaming, Rhyme Production, Rhyme identification, Production of words from a given phoneme, Identification of the initial phoneme, Phonemic analysis, Reading of words and nonwords, Phonemic Synthesis, Rapid Naming Speed using pictures, Syllabic segmentation, Silent reading, Auditory Comprehension of sentences from picture, and Phonological Working memory. Combined, these three factors (Pre-reading, Decoding, and Reading) accounted for $53.35 \%$ of the students' performance on the Protocol, and thus these factors would be statically sufficient to create a version of the protocol proposed. However, future 
studies are necessary to verify the exclusion of the 4 th factor (Auditory processing).

Our findings are in agreement with those found by Thompson et al. (2015), who indicated that early identification of "reading problems" is difficult, and the development of assessment protocols for this age and grade level are extremely important, as they can prevent future learning damages. Furthermore, our findings also suggest that early language problems can be considered as risk factors for dyslexia, but they can be also considered as risk factors for this disability for children entering school. Although Principal components Analysis revealed four factors, it is important to highlight that future analysis are still necessary to investigate the underlying factors affecting test items. However, if we take into account the educational reality in Brazil, the screening protocol proposed accomplished one of its main goals, which is helping professionals, such as teachers, Speech Language Therapists, and others to identify students at risk for dyslexia or other reading problems in 1st grade, since this type of protocols are practically non-existent in the country. In Brazil, one of the issues related to the identification of children at risk for dyslexia is the long period of time until they are referred to diagnostic centers. This results is consistent with the view that many children who have language delay and receive proper treatment can learn how to read. However, it is worth mentioning that these children continue at risk of having difficulties in reading skills and can present others difficulties, including social problems.

\section{CONCLUSION}

Results indicated that screening protocol developed in the present study showed four major factors: pre-reading (Letter-naming, Rhyme production, Rhyme identification, Production of words from a given phoneme, Identification of the initial phoneme); decodification (Phonemic synthesis, Phonemic analysis, Rapid Naming Speed using pictures, Reading of words and non-words);

\section{REFERENCES}

Alloway, T. P., Gathercole, S. E., Adams, A.-M., Willis, C., Eaglen, R., and Lamont, E. (2005). Working memory and phonological awareness as predictors of progress towards early learning goals at school entry. Br. J. Dev. Psychol. 23, 417-426. doi: 10.1348/026151005X26804

Andrade, O. V., Andrade, P. E., and Capellini, S. A., (2013). Identificação precoce do risco para transtornos da atenção e da leitura em sala de aula. Psicol. Teoria Pesqui. 29, 167-176. doi: 10.1590/S0102-377220130002 00006

Andrade, O. V. C. A., Prado, P. S. T., and Capellini, S. A., (2011). Desenvolvimento de ferramentas pedagógicas para identificação de escolares de risco para a dislexia. Rev. Psicopedag. 28, 14-28.

Araújo, S., Faísca, L., Reis, A., Marques, J. F., and Petersson, K. M. (2016). Visual naming deficits in dyslexia: an ERP investigation of different processing domains. Neuropsychologia 91, 61-76. doi: 10.1016/j.neuropsychologia.2016. 07.007

Araújo, S., Pacheco, A., Faísca, L., Petersson, K. M., and Reis, A. (2010). Visual rapid naming and phonological abilities: different subtypes in dyslexic children. Int. J. Psychol. 45, 443-452. doi: 10.1080/00207594.2010. 499949 reading (Silent Reading and Syllabic segmentation); and Auditory processing (Phonological working memory and comprehension of sentences from pictures) to identify Brazilian Portuguese speaking children at risk for dyslexia.

Based on the PCA carried out, our findings showed the effective use of the proposed Screening Protocol to analyze the predictive factors that can explain later reading achievement.

\section{ETHICS STATEMENT}

This study was carried out in accordance with the recommendations of 'Frontiers guidelines' with written informed consent from all subjects. All subjects gave written informed consent in accordance with the Declaration of Helsinki. The protocol was approved by the 'Ethics Committee of Faculty of Philosophy and Sciences, São Paulo State University "Júlio de Mesquita Filho" (FFC/UNESP).'

\section{AUTHOR CONTRIBUTIONS}

GG, AC, and SC had substantial contributions to the conception or design of the work; or the acquisition, analysis, or interpretation of data for the work; drafting the work or revising it critically for important intellectual content; final approval of the version to be published; agreement to be accountable for all aspects of the work in ensuring that questions related to the accuracy or integrity of any part of the work are appropriately investigated and resolved.

\section{ACKNOWLEDGMENTS}

The authors are grateful for the financial support provided by CNPq, The National Council for Scientific and Technological Development (Universal Notice MCT/CNPq number 14/2012).
Ashby, J. (2016). "Why does prosody accompany fluency? Re-conceptualizing the role of phonology in reading," in Reading Fluency, eds A. Khateb and I. BarKochva (Berlin: Springer International Publishing), 65-89. doi: 10.1007/978-3319-30478-6_5

Baddeley, A. D. (1986). Working Memory. Oxford: Oxford University Press.

Badian, N. A. (2001). Phonological and orthographic processing: their roles in reading prediction. Ann. Dyslexia 51, 179-202. doi: 10.1007/s11881-0010010-5

Bradley, L., and Bryant, P. E. (1983). Categorizing sounds and learning to read: a causal connection. Nature 301, 419-421. doi: 10.1038/301419a0

Brasil (1997). Secretaria de Educação Fundamental. Parâmetros Curriculares Nacionais: Língua Portuguesa. Brasília: Secretaria de Educação Fundamental.

Brizzolara, D., Chilosi, A., Cipriani, P., Di Filippo, G., Gasperini, F., Mazzotti, S., et al. (2006). Do phonologic and rapid automatized naming deficits differentially affect dyslexic children with and without a history of language delay? A study of Italian dyslexic children. Cogn. Behav. Neurol. 19, 141-149. doi: 10.1097/01.wnn.0000213902.59827.19

Brunswick, N., Martin, G. N., and Rippon, G. (2012). Early cognitive profiles of emergent readers: a longitudinal study.J. Exp. Child Psychol. 111, 268-285. doi: 10.1016/j.jecp.2011.08.001

Câmera, J. R. (1970a). Estrutura da Língua Portuguesa. Petrópolis: Vozes. 
Câmera, J. R. (1970b). Problemas de Linguística Descritiva, 3. Edn. Petrópolis: Vozes.

Capellini, S. A., César, A. B. P., and Germano, G. D. (2015). Early identification of reading problems: preliminary study with students of 1st grade. Proc. Soc. Behav. Sci. 174, 1351-1355. doi: 10.1016/j.sbspro.2015.01.758

Capellini, S. A., César, A. B. P., and Germano, G. D. (2017). Protocolo de Identificação Precoce dos Problemas de Leitura. Booktoy: Livraria e Editora.

Capellini, S. A., and Conrado, T. L. B. C. (2009). Desempenho de escolares com e sem dificuldades de aprendizagem de ensino particular em habilidade fonológica, nomeação rápida, leitura e escrita. Rev. CEFAC 11, 183-193. doi: 10.1590/S1516-18462009005000002

Capellini, S. A., Sampaio, M. N., Fukuda, M. T. M., Oliveira, A. M., Fadini, C. C., and Martins, M. A. (2009). Protocolo de identificação precoce dos problemas de leitura: estudo preliminar com escolares de 10 ano escolar. Rev. Psicopedag. $26,367-375$.

Cardoso-Martins, C., and Pennington, B. F. (2004). The relationship between phoneme awareness and rapid serial naming skills and literacy acquisition: the role of developmental period and reading ability. Sci. Stud. Read. 8, 27-52. doi: 10.1207/s1532799xssr0801_3

Carroll, J. M., Mundy, I. R., and Cunningham, A. J. (2014). The roles of family history of dyslexia, language, speech production and phonological processing in predicting literacy progress. Dev Sci. 17, 727-742. doi: 10.1207/ s1532799xssr0801_3

Catts, H. W., and Hogan, T. P. (2003). Language basis of reading disabilities and implications for early identification and remediation. Read Psychol. 24, 223-246. doi: 10.1080/02702710390227314

Cervera-Mérida, J. F., and Ygual-fernández, A. (2003). Intervención logopédica en los trastornos fonológicos desde el paradigma psicolingüístico del procesamiento del habla. Rev. Neurol. 36, 39-53.

Chard, D. J., and Dickson, S. V. (1999). Phonological awareness instructional and assessment guidelines. Interv. Sch. Clin. 34, 261-270. doi: 10.1007/BF0264 8171

Chaves-Sousa, S., Santos, S., Viana, F. L., Vale, A. P., Cadime, I., Prieto, G., et al. (2016). Development of a word reading test: identifying students at-risk for reading problems. Learn Individ. Diff. 56, 159-166. doi: 10.1016/j.lindif.2016. 11.008

Clark, H., and Clark, E. (1977). Psychology and Language. New York, NY: Harcourt Brace Jovanovic.

Coltheart, M., Rastle, K., Perry, C., Langdon, R., and Ziegler, J. (2001). DRC: a dual route cascaded model of visual word recognition and reading aloud. Psychol. Rev. 108:204. doi: 10.1037/0033-295X.108.1.204

De Groot, B. J., Van den Bos, K. P., Van der Meulen, B. F., and Minnaert, A. E. (2017). Rapid naming and phonemic awareness in children with or without reading disabilities and/or ADHD. J. Learn. Disabil. 50, 168-179. doi: 10.1177/ 0022219415609186

De Jong, P. F., and Olson, R. K. (2004). Early predictors of letter knowledge. J. Exp. Child Psychol. 88, 254-273. doi: 10.1016/j.jecp.2004.03.007

De Jong, P. F., and Van der Leij, A. (1999). Specific contributions of phonological abilities to early reading acquisition: results from a Dutch latent variable longitudinal study. J. Educ. Psychol. 91, 450-476. doi: 10.1037/00220663.91.3.450

Denckla, M. B., and Rudel, R. (1976). Rapid “automatized” naming (RAN): dyslexia differentiated from other learning disabilities. Neuropsychologia 14, 471-479. doi: 10.1016/0028-3932(76)90075-0

Duncan, L. G., Castro, S. L., Defior, S., Seymour, P. H., Baillie, S., Leybaert, J., et al. (2013). Phonological development in relation to native language and literacy: variations on a theme in six alphabetic orthographies. Cognition 127, 398-419. doi: 10.1016/0028-3932(76)90075-0

Ehri, L. C. (1997). "Learning to read and learning to spell are one and the same, almost," in Learning to spell: Research, Theory, and Practice Across Languages, eds C. A. Perfetti, L. Rieben, and M. Fayol (Mahwah, NJ: Lawrence Erlbaum Associates), 237-268.

Fadini, C. C., and Capellini, S. A. (2011). Treinamento de habilidades fonológicas em escolares de risco para dislexia. Rev. Psicopedag. 28, 3-13.

Franceschini, S., Gori, S., Ruffino, M., Pedrolli, K., and Facoetti, A. (2012). A causal link between visual spatial attention and reading acquisition. Curr. Biol. 22, 814-819. doi: 10.1016/j.cub.2012.03.013
Fukuda, M. T. M., and Capellini, S. A. (2011). Treinamento de habilidades fonológicas e correspondência grafema-fonema em crianças de risco para dislexia. Rev. CEFAC 13, 227-235. doi: 10.1590/S1516-18462010005000074

Fukuda, M. T. M., and Capellini, S. A. (2012). Programa de Intervenção Fonológica associado à correspondência grafema-fonema em escolares de risco para a dislexia. Psicol. Refl. Crít. 25, 783-790. doi: 10.1590/S0102-79722012000 400018

Galin, D., Raz, J., Fein, G., Johnstone, J., Herron, J., and Yingling, C. (1992). EEG spectra in dyslexic and normal readers during oral and silent reading. Electroencephalogr. Clin. Neurophysiol. 82, 87-101. doi: 10.1016/0013-4694(92) 90151-7

Gathercole, S. E., and Baddeley, A. D. (1989). Evaluation of the role of phonological STM in the development of vocabulary in children: a longitudinal study. J. Mem. Lang. 28, 200-213. doi: 10.1016/0749-596X(89)90044-2

Gathercole, S. E., Service, E., Hitch, G. J., Adams, A. M., and Martin, A. J. (1999). Phonological short-term memory and vocabulary development: further evidence on the nature of the relationship. Appl. Cogn. Psychol. 13, 65-77. doi: 10.1002/(SICI) 1099-0720(199902)13:1<65::AID-ACP548>3.0.CO;2-O

Gathercole, S. E., Willis, C. S., Baddeley, A. D., and Emslie, H. (1994). The children's test of nonword repetition: a test of phonological working memory. Memory 2, 103-127. doi: 10.1080/09658219408258940

Germano, G. D. (2011). Instrumento de Avaliação Metafonológica Para Caracterização de Escolares com Dislexia, Transtornoe Dificuldades de Aprendizagem. Doctorate's thesis, Universidade Estadual Paulista Júlio de Mesquita Filho, Marília.

Germano, G. D., and Capellini, S. A. (2008). Eficácia do programa de remediação auditivo-visual computadorizado em escolares com dislexia. Pró Fono Rev. Actual. Cient. 20, 237-242. doi: 10.1590/S0104-56872008000400006

Germano, G. D., and Capellini, S. A. (2011). Performance of students with dyslexia, learning disabilities and learning difficulties in metaphonological abilities tests (PROHFON). J. Soc. Bras. Fonoaudiol. 23, 135-141. doi: 10.1590/ S2179-64912011000200010

Germano, G. D., Reilhac, C., Capellini, S. A., and Valdois, S. (2014). The phonological and visual basis of developmental dyslexia in Brazilian Portuguese reading children. Front. Psychol. 5:1169. doi: 10.3389/fpsyg.2014.01169

Gipstein, M., Brady, S., and Fowler, A. (2001). "Questioning the role of syllables and rimes in early phonological awareness," in Early Identification and Remediation of Reading Disability, Second Edn, ed. M. Masland (Parkton, MD: York Press), $179-216$.

Godoy, D. M., and Pinheiro, A. (2013). O Que Sabemos Sobre A Contribuição da Consciência Fonêmica Para A Aprendizagem Inicial da Leitura e da Escrita. A Aprendizagem da Leitura e da Escrita. São Paulo: Vetor.

Gombert, J. E. (2003). "Atividades metalinguísticas e aprendizagem da leitura," in Metalinguagem e Aquisição da Escrita: Contribuiçães da Pesquisa Para a Prática da Alfabetização, ed. M. R. Maluf (São Paulo: Casa do Psicólogo), 19-63.

Gough, P. B., and Tunmer, W. E. (1986). Decoding, reading, and reading disability. Remedial Spec. Educ. 7, 6-10. doi: 10.1177/074193258600700104

Hayes, R., and Slater, A. (2008). Three month-olds'detection of alliteration in syllables. Infant Behav. Dev. 31, 153-156. doi: 10.1016/j.infbeh.2007. 07.009

Hoover, W. A., and Gough, P. B. (1990). Read Writ, Vol. 2. Dordrecht: Kluwer Academic Publishers, 127. doi: 10.1007/BF00401799

Hulme, C., Nash, H. M., Gooch, D., Lervåg, A., and Snowling, M. J. (2015). The foundations of literacy development in children at familial risk of dyslexia. Psychol. Sci. 26, 1877-1886. doi: 10.1177/0956797615603702

Hulme, C., and Snowling, M. J. (2014). The interface between spoken and written language: developmental disorders. Philos. Trans. R. Soc. Lond. B Biol. Sci. 369:20120395. doi: 10.1098/rstb.2012.0395

Johnston, T. C., and Kirby, J. R. (2006). The contribution of naming speed to the simple view of reading. Read. Writ. 19, 339-361. doi: 10.1007/s11145-0054644-2

Jones, M. W., Branigan, H. P., Hatzidaki, A., and Obregón, M. (2010). Is the 'naming' deficit in dyslexia a misnomer? Cognition 116, 56-70. doi: 10.1016/ j.cognition.2010.03.015

Kim, Y. S., Petscher, Y., Schatschneider, C., and Foorman, B. (2010). Does growth rate in oral reading fluency matter in predicting reading comprehension achievement? J. Educ. Psychol. 102, 652-667. doi: 10.1037/a0019643 
Kirby, J. R., Georgiou, G. K., Martinussen, R., and Parrila, R. (2010). Naming speed and reading: from prediction to instruction. Read. Res. Q. 45, 341-362. doi: 10.1598/RRQ.45.3.4

Law, J. M., Wouters, J., and Ghesquière, P. (2016). The influences and outcomes of phonological awareness: a study of MA, PA and auditory processing in prereaders with a family risk of dyslexia. Dev. Sci. 20:12453. doi: 10.1111/desc. 12453

Lerner, M. D., and Lonigan, C. J. (2016). Bidirectional relations between phonological awareness and letter knowledge in preschool revisited: a growth curve analysis of the relation between two code-related skills. J. Exp. Child Psychol. 144, 166-183. doi: 10.1016/j.jecp.2015.09.023

Lonigan, C. J., Anthony, J. L., Phillips, B. M., Purpura, D. J., Wilson, S. B., and McQueen, J. D. (2009). The nature of preschool phonological processing abilities and their relations to vocabulary, general cognitive abilities, and print knowledge. J. Educ. Psychol. 101, 345-358. doi: 10.1037/a0013837

Majerus, S., and Cowan, N. (2016). The nature of verbal short-term impairment in dyslexia: the importance of serial order. Front. Psychol. 7:1522. doi: 10.3389/ fpsyg.2016.01522

Manz, P. H., Hughes, C., Barnabas, E., Bracaliello, C., and Ginsburg-Block, M. (2010). A descriptive review and meta-analysis of family-based emergent literacy interventions: to what extent is the research applicable to low-income, ethnic-minority or linguistically-diverse young children? Early Child. Res. Q. 25, 409-431. doi: 10.1016/j.ecresq.2010.03.002

Montgomery, J. W. (1995). Sentence comprehension in children with specific language impairment: the role of phonological working memory. J. Speech Lang. Hear. 38, 187-199. doi: 10.1044/jshr.3801.187

Morris, R. D., Lovett, M. W., Wolf, M., Sevcik, R. A., Steinbach, K. A., Frijters, J. C., et al. (2012). Multiple-component remediation for developmental reading disabilities: IQ, socioeconomic status, and race as factors in remedial outcome. J. Learn. Disabil. 45, 99-127. doi: 10.1177/0022219409355472

Morris, R. D., Stuebing, K. K., Fletcher, J. M., Shaywitz, S. E., Lyon, G. R., Shankweiler, D. P., et al. (1998). Subtypes of reading disability: variability around a phonological core. J. Educ. Psychol. 90, 347-373. doi: 10.1037/00220663.90.3.347

Mota, M. M. P. E., Vieira, M. T., Bastos, R. R., Dias, J., Paiva, N., Mansur-Lisboa, S., et al. (2012). Contextual reading and metalinguistic processing in brazilian portuguese: a longitudinal study. Psicol. Refl. Crít. 25, 114-120. doi: 10.1590/ S0102-79722012000100014

Norton, E. S., and Wolf, M. (2012). Rapid automatized naming (RAN) and reading fluency: Implications for understanding and treatment of reading disabilities. Annu. Rev. Psychol. 63, 427-452. doi: 10.1146/annurev-psych-120710-100431

Oliveira, A. M. D., and Capellini, S. A. (2010). Desempenho de escolares na adaptação brasileira da avaliação dos processos de leitura. Pró Fono R. Atual. Cient. 22, 555-560. doi: 10.1590/S0104-56872010000400033

Ortiz, M., Folsom, J. S., Otaiba, S. A., Greulich, L., Thomas-Tate, S., and Connor, C. M. (2012). The componential model of reading: predicting first grade reading performance of culturally diverse students from ecological, psychological, and cognitive factors assessed at kindergarten entry. J. Learn. Disabil. 45, 406-417. doi: $10.1177 / 0022219411431242$

Ouellette, G. P., and Haley, A. (2013). One complicated extended family: the influence of alphabetic knowledge and vocabulary on phonemic awareness. $\imath \mathrm{J}$. Read. Res. 36, 29-41. doi: 10.1111/j.1467-9817.2010.01486.x

Pennington, B. F., and Lefly, D. L. (2001). Early reading development in children at family risk for dyslexia. Child Dev. 72, 816-833. doi: 10.1111/1467-8624.00317

Peterson, R. L., and Pennington, B. F. (2012). Developmental dyslexia. Lancet 379, 1997-2007. doi: 10.1016/S0140-6736(12)60198-6

Pinheiro, A. M. V., Cunha, C. R., and Lúcio, P. S. (2008). Tarefa de leitura de palavras em voz alta: uma proposta de análise dos erros. Rev. Port. Educ. 21, $115-138$.

Rack, J. P., Snowling, M. J., and Olson, R. K. (1992). The nonword reading deficit in developmental dyslexia: a review. Read. Res. Q. 27, 29-53. doi: 10.2307/747832

Ramus, F., and Ahissar, M. (2012). Developmental dyslexia: the difficulties of interpreting poor performance, and the importance of normal performance. J. Cogn. Neurosci. 29, 104-122. doi: 10.1080/02643294.2012. 677420
Scliar-Cabral, L. (2003). Princípios do Sistema Alfabético do Português do Brasil. São Paulo: Contexto.

Secretaria da Educação do Estado de São Paulo (2014). Relatório Pedagógico de Língua Portuguesa (Saresp). São Paulo: Secretaria da Educação do Estado de São Paulo.

Selkirk, E. O. (1982). “The syllable," in The Structure of Phonological Representations, eds H. Van der Hulst and N. Smith (Dordrecht: Foris Publications).

Share, D. L. (1995). Phonological recoding and self-teaching: sine qua non of reading acquisition. Cognition 55, 151-218. doi: 10.1016/0010-0277(94) 00645-2

Shaywitz, S. E., and Shaywitz, B. A. (2005). Dyslexia (specific reading disability). Biol. Psychiatry 57, 1301-1309. doi: 10.1016/j.biopsych.2005.01.043

Silva, C. D., and Capellini, S. A. (2013). Desempenho de escolares com e sem transtorno de aprendizagem em leitura, escrita, consciência fonológica, velocidade de processamento e memória de trabalho fonológica. Rev. Psicopedag. 30, 3-11.

Silvén, M., Niemi, P., and Voeten, M. J. (2002). Do maternal interaction and early language predict phonological awareness in 3-to 4-year-olds? Cogn. Dev. 17, 1133-1155. doi: 10.1016/S0885-2014(02)00093-X

Skeide, M. A., Kirsten, H., Kraft, I., Schaadt, G., Müller, B., Neef, N., et al. (2015). Genetic dyslexia risk variant is related to neural connectivity patterns underlying phonological awareness in children. Neuroimage 118, 414-421. doi: 10.1016/j.neuroimage.2015.06.024

Snowling, M. J. (2013). Early identification and interventions for dyslexia: a contemporary view. JORSEN 13, 7-14. doi: 10.1111/j.1471-3802.2012.01262.x

Thompson, P. A., Hulme, C., Nash, H. M., Gooch, D., Hayiou-Thomas, E., and Snowling, M. J. (2015). Developmental dyslexia: predicting individual risk. J. Exp. Child Psychol. 56, 976-987. doi: 10.1111/jcpp.12412

Vaessen, A., Gerretsen, P., and Blomert, L. (2009). Naming problems do not reflect a second independent core deficit in dyslexia: double deficits explored. J. Exp. Child Psychol. 103, 202-221. doi: 10.1016/j.jecp.2008.12.004

van den Boer, M., van Bergen, E., and de Jong, P. F. (2014). Underlying skills of oral and silent reading. J. Exp. Child Psychol. 128, 138-151. doi: 10.1016/j.jecp.2014. 07.008

Wagner, R. K., and Torgesen, J. K. (1987). The nature of phonological processing and its causal role in the acquisition of reading skills. Psychol. Bull. 101, 192-212. doi: 10.1016/j.jecp.2011.11.007

Wolf, M., and Bowers, P. G. (1999). The double-deficit hypothesis for the developmental dyslexia. J. Educ. Psychol. 91, 415-438. doi: 10.1037/0022-0663. 91.3.415

Wolf, M., Bowers, P. G., and Biddle, K. (2000). Naming-speed processes, timing, and reading a conceptual review. J. Learn. Disabil. 33, 387-407. doi: 10.1177/ 002221940003300409

Zhao, J., Kwok, R. K., Liu, M., Liu, H., and Huang, C. (2016). Underlying skills of oral and silent reading fluency in chinese: perspective of visual rapid processing. Front. Psychol. 7:2082. doi: 10.3389/fpsyg.2016.02082

Ziegler, J. C., Castel, C., Pech-Georgel, C., George, F., Alario, F. X., and Perry, C. (2008). Developmental dyslexia and the dual route model of reading: simulating individual differences and subtypes. Cognition 107, 151-178. doi: 10.1016/j. cognition.2007.09.004

Ziegler, J. C., and Goswami, U. (2006). Becoming literate in different languages: similar problems, different solutions. Dev. Sci. 9, 429-436. doi: 10.1111/j.14677687.2006.00509.x

Conflict of Interest Statement: The authors declare that the research was conducted in the absence of any commercial or financial relationships that could be construed as a potential conflict of interest.

Copyright (c) 2017 Germano, César and Capellini. This is an open-access article distributed under the terms of the Creative Commons Attribution License (CC BY). The use, distribution or reproduction in other forums is permitted, provided the original author(s) or licensor are credited and that the original publication in this journal is cited, in accordance with accepted academic practice. No use, distribution or reproduction is permitted which does not comply with these terms. 